\title{
Effects of Holding Time on Thermomechanical Fatigue Properties of Compacted Graphite Iron Through Tests with Notched Specimens
}

\author{
SEPIDEH GHODRAT, TON A.C. RIEMSLAG, LEO A.I. KESTENS, \\ ROUMEN H. PETROV, MICHAEL JANSSEN, and JILT SIETSMA
}

\begin{abstract}
In cylinder heads of compacted graphite iron (CGI), the heating and cooling cycles can lead to localized cracking due to thermomechanical fatigue (TMF). Traditionally, TMF behavior is studied by thermal cycling of smooth specimens. The resulting number of cycles to failure $\left(N_{\mathrm{f}}\right)$ constitutes a single parameter that can be used to predict actual service failures. Nevertheless, there are also some drawbacks of the conventional testing procedures, most noticeably the prolonged testing times and a considerable scatter in test results. To address these drawbacks, TMF tests were performed using notched specimens, resulting in shorter testing times with less scatter. In the case of cast iron, artificial notches do not necessarily change the TMF behavior since the inherent graphite particles behave as internal notches. Using a notch depth of $0.2 \mathrm{~mm}$, the effect of prolonged holding times (HT) on TMF lifetime was studied and a clear effect was found. Extended holding times were also found to be accompanied by relaxation of compressive stresses, causing higher tensile stresses to develop in the subsequent low temperature stages of the TMF cycles. The lifetimes in notched CGI specimens can be predicted by the Paris' fatigue crack growth model. This model was used to differentiate between the individual effects of stress level and holding times on TMF lifetime. Microstructural changes were evaluated by analyzing quantitative data sets obtained by orientation contrast microscopy based on electron backscattered diffraction (EBSD).
\end{abstract}

DOI: $10.1007 / \mathrm{s} 11661-012-1320-4$

(C) The Author(s) 2012. This article is published with open access at Springerlink.com

\section{INTRODUCTION}

CAST iron components in engines, such as cylinder blocks and heads, are exposed for long periods of time to elevated temperatures and are subjected to large numbers of heating and cooling cycles. In complex components, these cycles can lead to localized cracking of the cast iron due to stresses that develop as a result of thermal gradients and thermal mismatch. This phenomenon is known as thermomechanical fatigue (TMF).

"In a combustion engine, the TMF phenomenon is related to the start-operate-stop cycles and not to the combustion cycles." ${ }^{[1]}$ Especially the valve bridges in cylinder heads, the areas between intakes and outtakes are severely subjected to so called out-of-phase (OP)

SEPIDEH GHODRAT, Ph.D. Research Student, is with the Materials Innovation Institute (M2i), 2628 CD Delft, The Netherlands, and also with the Department of Materials Science and Engineering, Delft University of Technology, 2628 CD Delft, The Netherlands. Contact e-mails: s.ghodrat@tudelft.nl; s.ghodrat@m2i.nl TON A.C. RIEMSLAG, Consultant of Mechanical Testing \& Behaviour, MICHAEL JANSSEN, Associate Professor, and JILT SIETSMA, Professor, are with the Department of Materials Science and Engineering, Delft University of Technology. LEO A.I. KESTENS, Professor, and ROUMEN H. PETROV, Associate Professor, are with the Department of Materials Science and Engineering, Delft University of Technology, and also with the Department of Materials Science and Engineering, Ghent University, 9052 Gent, Belgium.

Manuscript submitted March 26, 2012.

Article published online July 20, 2012 loading, where a maximum tensile stress occurs at the minimum temperature level of the cycles, and vice versa. $^{[1]}$

According to Löhe et al. ${ }^{[2]}$ multiple mechanisms take place during a thermomechanical out-of-phase cycle: plastic deformation, creep, oxidation, coarsening of the microstructure, and crack initiation and propagation. However, these damage mechanisms significantly depend on the material, temperature, frequency, mean stress level, and environment. ${ }^{[3]}$ The main damage mechanisms are mechanical damage by fatigue, viscous phenomena by stress relaxation/creep, and environmental damage by oxidation. ${ }^{[4]}$ Gocmez et al. ${ }^{[4]}$ point out that in damage models the oxidation process is defined as a function of strain range, strain rate, straintemperature phasing, and oxidation kinetics. They claim that creep damage is based on stress, temperature, strain-temperature phasing, and time. Both mechanical and oxidation damage mechanisms are temperature and time dependent, which is relevant for TMF since this takes place during prolonged periods of time at various temperatures. In addition to these phenomena, in the case of cast iron, the graphite particles affect the deformation. As discussed by Seifert and Riedel ${ }^{[5]}$ and Seifert et al. ${ }^{[5,6]}$ graphite particles in cast iron weaken the material in tension by decreasing the stiffness since the graphite particles partly delaminate from the matrix. In compression, interfacial microcracks are closed and a higher stiffness results. This leads to an asymmetrical 
tension-compression behavior of cast iron. ${ }^{[5]}$ It was found that in compression the Young's modulus on average is 5 pct larger than in tension. ${ }^{[7]}$

Generally, an in-service thermal cycle of a diesel engine contains an extended holding time during the heating and cooling phases. In OP-TMF, the maximum compressive stress occurs during the upper cycle temperature. The influence of the holding time at maximum operating temperature has been evaluated by many researchers and was first reported by Gundlach. ${ }^{[8]}$ In order to study the response of cast iron undergoing thermal cycling, he performed TMF tests on different types of cast irons. His results revealed that during thermal cycling, the compressive stress at maximum temperature decreased with the number of cycles, while the tensile stress at minimum temperature increased. Consequently, Gundlach concluded that stress relaxation was taking place, ultimately reducing the TMF life of specimens. It is reported that cast irons under TMF conditions undergo short-term stress relaxation within time periods of the order of only minutes. ${ }^{[9]}$ The results of relaxation experiments performed for nodular cast iron show that after half an hour, the stress decreased by 30 pet at $723 \mathrm{~K}\left(450{ }^{\circ} \mathrm{C}\right)$ and 50 pet at $773 \mathrm{~K}\left(500^{\circ} \mathrm{C}\right) .{ }^{[6]}$

It should be noted that for fatigue in general, it is not apparent to consider stress relaxation as a damaging mechanism, since reduction of stresses is more likely to slow down fatigue processes. However, in the specific case of TMF (under total constraint conditions), stress relaxation during the compressive part of a TMF cycle causes a higher tensile stress to develop in the subsequent tensile part of the TMF load cycle. This increased stress level in tension is considered to induce damage and, hence, reduce TMF lifetime. The matter of increasing tensile stresses due to relaxation of compressive stresses is discussed in more detail in Section III-A.

With regard to testing procedures, conventionally the TMF behavior is studied by cyclically loading smooth specimens until failure. Both the crack-initiation and the crack-growth phases determine the test result, which can be useful to predict actual service failures. Explicit information on the initiation phase is of importance since for the most part, this phase generally determines the TMF lifetime of materials with a homogeneous microstructure (i.e., not considering cast iron). Unfortunately, standard test methods do not provide this information.

In the case of cast iron, its microstructure allows an alternative approach, which consists of performing TMF tests on notched specimens. Even TMF test results on notched specimens maintain their relevance to actual field failures of (unnotched) structural components. Adding a surface notch with a dimension similar to that of graphite particles has an effect equivalent to the presence of a large graphite particle. The reason is that the initiation of a fatigue crack is likely to be accelerated by the presence of graphite particles. For instance, in the case of high cycle fatigue of nodular cast iron, a clear relation between the fatigue lifetime and the graphite dimensions has been established. ${ }^{[10]}$

The idea is based on the fact that cast iron contains a high fraction of relatively large graphite particles. Mechanically, the graphite regions can be considered as internal defects or notches. It is reasonable to assume that in this material, cracks are easily initiated at the graphite particles during the first cycles and that, therefore, the crack initiation period is rather short. Under TMF loading conditions, fatigue cracks nucleate early in lifetime, while most of fatigue life is spent with crack propagation. ${ }^{[5]}$

In previous research, the effect of holding time on TMF lifetime was studied using smooth specimens of compacted graphite iron (CGI) material. ${ }^{[7]}$ A reduction of TMF lifetime was found at longer holding times, but the results were clouded by a relatively large scatter in test results. Therefore, an alternative TMF test method for CGI material was introduced, using notched specimens, resulting in shorter testing times with a reduced amount of scatter. By using different notch depths, it was demonstrated that the TMF lifetime in CGI could be predicted by the Paris' crack growth law. For smooth samples, the typical graphite particles were found to act as inherent notches, for which the Paris model prediction could also be used successfully (with the notch depth corresponding to the typical graphite particle size). In this respect, there is no fundamental difference in the TMF response of smooth and notched specimens.

In the current research, the effect of holding time on the TMF behavior of CGI is studied using notched specimens. In this way, the total testing time is kept reasonably short in spite of the extended holding times per cycle. Moreover, the scatter is expected to be less compared to test results on smooth specimens.

For an effective reduction of scatter, the notch depth must be notably larger than the typical graphite particle size (i.e., $50 \mu \mathrm{m}$ ), and in this respect, a notch depth of $0.2 \mathrm{~mm}$ is suitable. Choosing a larger notch depth would reduce both scatter and testing time even more. However, the testing time must remain sufficiently long for the environment to have enough time to interact with the TMF micromechanisms. Therefore, a notch depth of $0.2 \mathrm{~mm}$ provides a balance between a reduced scatter and a sufficiently long testing time.

In the current research, the microstructural evolution of CGI will be investigated by the powerful technique of orientation contrast microscopy, which is based on electron backscattering diffraction (EBSD). More precisely, with this technique, it is intended to reveal very subtle microstructural changes induced by microplastic strain and ensuing recovery during a first typical TMF cycle. Orientation contrast microscopy allows observing minute orientation changes (of the order of less than $1 \mathrm{deg}$ ), which are reminiscent and characteristic of the phenomena under consideration.

\section{EXPERIMENTAL PROCEDURE}

\section{A. Material}

The material investigated in this work is CGI with a pearlitic matrix. The nominal chemical composition of the material is given in Table I.

Figure 1 illustrates the complex morphology of compacted graphite iron. The microstructure is composed of 
Table I. Nominal Chemical Composition of the CGI (wt pet)

\begin{tabular}{lccccccc}
\hline $\mathrm{C}$ & $\mathrm{Ti}$ & $\mathrm{Cr}$ & $\mathrm{Mn}$ & $\mathrm{Cu}$ & $\mathrm{Sn}$ & $\mathrm{Pb}$ & $\mathrm{Si}$ \\
\hline 3.60 to 3.90 & $<0.015$ & $<0.10$ & 0.15 to 0.40 & 0.75 to 0.95 & 0.06 to 0.10 & $<0.002$ & 1.90 \\
\hline
\end{tabular}

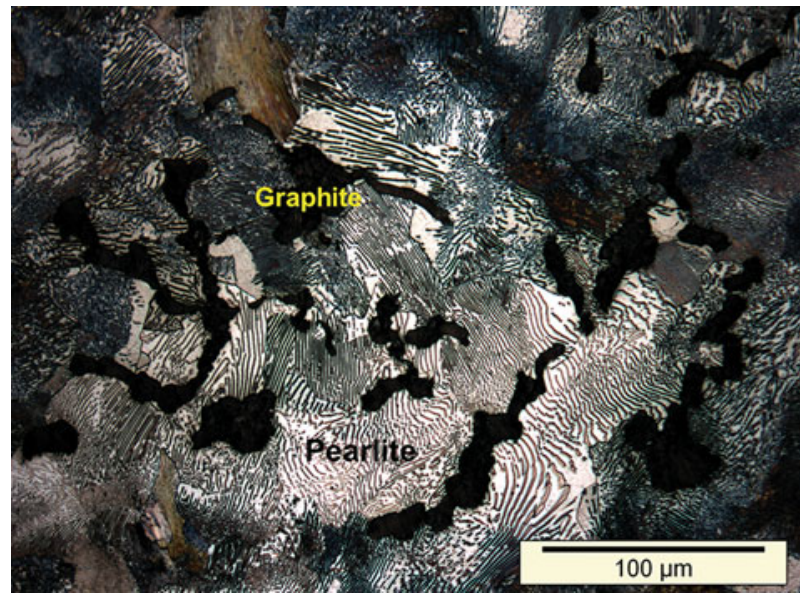

Fig. 1-Microstructure of the pearlitic CGI under investigation.

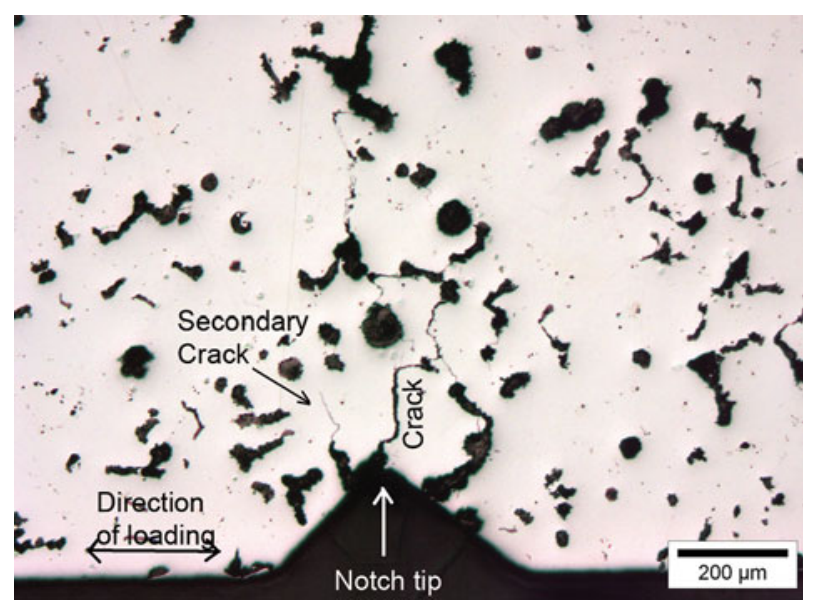

Fig. 2-Cross section of TMF loaded specimen, with a notch of $0.2 \mathrm{~mm}$, showing graphite particles in the vicinity of the notch root and cracks emanating from the graphite particles (unetched).

graphite particles embedded in a pearlite matrix, with a variety of lamellar structures and a small fraction of ferrite.

\section{B. Test Procedures}

TMF experiments were conducted using a $25 \mathrm{kN}$ MTS servohydraulic fatigue machine (MTS Systems Corporation, Eden Prairie, MN) capable of imposing independent temperature and strain profiles on a test specimen. Solid, smooth, dogbone specimens were taken out of cylinder heads and machined to a final smooth cylindrical gauge length of $22.0 \pm 0.25 \mathrm{~mm}$ and a diameter of $\varnothing 6.00 \pm 0.025 \mathrm{~mm}$. The reduced section of the specimens was machined by a turning operation, with the final two steps removing only $0.05 \mathrm{~mm}$ of the thickness to prevent internal stresses near the surface. In a next step, specimens were provided with a circumferential notch in the middle of the gauge length, with a depth of $0.2 \mathrm{~mm}$ and a $0.04 \mathrm{~mm}$ tip radius ( $c f$. Figure 2). Cracks were always found to initiate from graphite particles at or near the notch tip, and in this respect, a possible influence of surface roughness on TMF lifetime (as would be the case when using smooth specimens) can be excluded when using notched specimens.

A high-frequency induction generator was used for heating. Cooling was accomplished by blowing compressed air from three sides onto the specimen and by thermal conduction into the water-cooled specimen grips. The temperature was measured and controlled by two K-type thermocouples that were pressed onto the surface of the specimen. One thermocouple was placed at a location approximately 0.5 to $1.0 \mathrm{~mm}$ above the notch. The other thermocouple was used to control the temperature located at 0.5 to $1.0 \mathrm{~mm}$ below the notch.

The contact pressure of the thermocouples is regulated by means of a spring configuration. This is found to lead to a good contact with the specimen surface and an accurate temperature measurement. The temperature gradient observed is within the requirements of the European code of practice for strain-controlled thermomechanical fatigue testing. ${ }^{[11]}$

The axial strain was measured via an air-cooled, hightemperature, ceramic rod extensometer with $12 \mathrm{~mm}$ gauge length. TMF tests were performed under full constraint conditions, meaning that the total strain measured by the extensometer was kept constant. By cycling the temperature between $323 \mathrm{~K}$ and $693 \mathrm{~K}$ $\left(50{ }^{\circ} \mathrm{C}\right.$ and $\left.420^{\circ} \mathrm{C}\right)$, OP TMF loading was accomplished. This TMF test procedure is intended to replicate the thermal and mechanical conditions in the valve bridge area of cylinder heads. The heating and cooling rates were $9 \mathrm{~K} \mathrm{~s}^{-1}$ and $6 \mathrm{~K} \mathrm{~s}^{-1}$, respectively.

The thermal cycles are shown schematically in Figure 3. Holding times were introduced to represent the in-service conditions that valve bridges are subjected to. However, holding times were selected to have reasonable testing times. Three different holding times at the maximum temperature $693 \mathrm{~K}\left(420{ }^{\circ} \mathrm{C}\right)$ of $30 \mathrm{sec}-$ onds, 480 seconds, and 1800 seconds were chosen in combination with 30 seconds for the minimum temperature $323 \mathrm{~K}\left(50{ }^{\circ} \mathrm{C}\right)$. Using different holding times at $693 \mathrm{~K}\left(420{ }^{\circ} \mathrm{C}\right)$ allows stress relaxation to occur to different degrees. The choice of holding times is based on previously performed compressive stress relaxation experiments at $693 \mathrm{~K}\left(420^{\circ} \mathrm{C}\right) .{ }^{[7]}$

The microstructural evolution during a typical TMF heating stage was evaluated by performing EBSD measurements in order to find the mechanisms associated with the stress relaxation phenomena. To this 
purpose, a CGI sample with a rectangular cross section of $9 \times 7 \mathrm{~mm}^{2}$, and a height of $17 \mathrm{~mm}$ was fabricated, which is designated as a parallelepipoid-shaped specimen. The small size of the specimen accommodates the positioning of the specimen within the confined space of the scanning electron microscope (SEM) sample chamber.

The EBSD measurements were performed for three conditions of the CGI material, being (1) as-cast (point A in Figure 3), (2) heated in total constraint but without holding time (point B in Figure 3), and (3) heated in total constraint with a 1800 seconds holding time (point $\mathrm{C}$ in Figure 3).

To enable the EBSD measurements, one side of the parallelepipoid-shaped specimen $\left(9 \times 17 \mathrm{~mm}^{2}\right)$ was prepared with a final polishing step using OPS $(0.25 \mu \mathrm{m})$, manually polishing the surface for 40 minutes. In the center of the polished surface, three microindentions were made to mark a specific location. At this location, ESBD measurements were performed, characterizing the situation of the as-cast state of the material (point A in Figure 3).

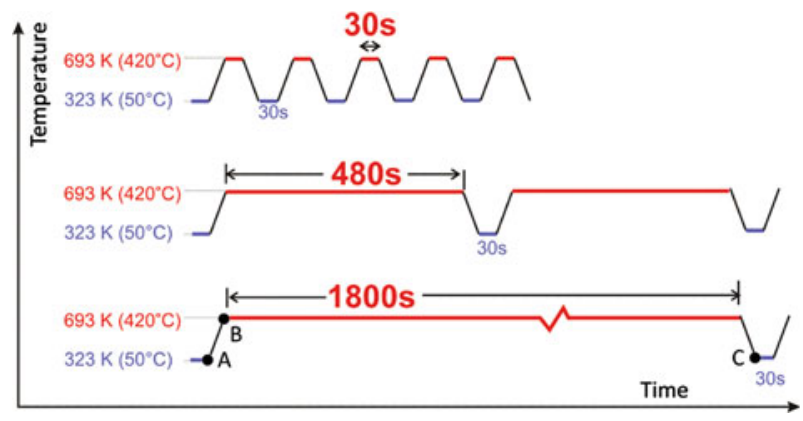

Fig. 3-Three different holding times at maximum temperature $693 \mathrm{~K}\left(420^{\circ} \mathrm{C}\right)$ of $30 \mathrm{~s}, 480 \mathrm{~s}$, and $1800 \mathrm{~s}$ were chosen in combination with $30 \mathrm{~s}$ for the minimum temperature $323 \mathrm{~K}\left(50^{\circ} \mathrm{C}\right)$.
To obtain the condition represented by point $\mathrm{B}$ of the CGI material (Figure 3), two cylindrical pushing rods $(\varnothing=12 \mathrm{~mm})$ were clamped in the grips of the TMF fatigue machine. The parallelepipoid-shaped specimen was placed between the ends of the cylindrical pushing rods and heated to $693 \mathrm{~K}\left(420{ }^{\circ} \mathrm{C}\right.$ ) (at the rate of $9 \mathrm{~K} \mathrm{~s}^{-1}$ ) under total constraint. When reaching the temperature to $693 \mathrm{~K}\left(420^{\circ} \mathrm{C}\right)$, a peak compressive stress was reached and the test was stopped, after which the specimen was removed. One side of the specimen was then polished and analyzed by ESBD, giving microstructural information in the condition represented by point $\mathrm{B}$ in Figure 3. The ESBD measurements were done at the same location as was done for the as-cast condition.

Finally, to characterize the condition represented by point $\mathrm{C}$ (Figure 3 ), the specimen was again placed in the TMF machine and heated to a temperature of $693 \mathrm{~K}$ $\left(420{ }^{\circ} \mathrm{C}\right.$ ) (at the rate of $\left.9 \mathrm{~K} \mathrm{~s}^{-1}\right)$, after which the peak compression level of the condition represented by point B was applied, while maintaining the temperature of $693 \mathrm{~K}\left(420^{\circ} \mathrm{C}\right)$. At the point of reaching the peak compressive stress, the strain was kept constant for a period of 1800 seconds, allowing stress relaxation to occur (point $\mathrm{C}$ in Figure 3). After this holding time, the test was ended and the specimen surface was repolished for observation by EBSD at exactly the same location as studied before. The EBSD measurements were done on a scanning area of $430 \times 300 \mu \mathrm{m}^{2}$ with a step size of $1.4 \mu \mathrm{m}$.

\section{RESULTS AND DISCUSSION}

\section{A. Lifetime $\left(N_{f}\right)$, Stress, and Plastic Strain Evolutions with Holding Times}

The results of tests with different holding times are listed in Table II. In this table, the TMF lifetime $N_{10}$ is defined as the number of cycles at which the maximum

Table II. Experimental and Calculated Results for TMF Tests: Stresses are Nominal Values, i.e., Based on a Circular Cross Section of $6 \mathrm{~mm}$ Diameter

\begin{tabular}{|c|c|c|c|c|c|c|}
\hline \multirow[b]{2}{*}{$\begin{array}{l}\text { Holding } \\
\text { Time (s) }\end{array}$} & \multicolumn{4}{|c|}{ Experimental Values } & \multicolumn{2}{|c|}{ Calculated Values } \\
\hline & $\begin{array}{c}\text { Lifetime } \\
N_{10}, \text { cycles }\end{array}$ & $\begin{array}{c}\text { Average } \\
\text { Lifetime } \\
N_{10} \text {, cycles }\end{array}$ & $\begin{array}{c}\text { Maximum } \\
\text { Stress } \\
\text { Level (MPa) }\end{array}$ & $\begin{array}{c}\text { Average } \\
\text { Maximum } \\
\text { Stress } \\
\text { Level (MPa) }\end{array}$ & $C_{\text {Paris }}^{* \pm}$ & $\begin{array}{c}\text { Corrected } \\
\text { Lifetime } \\
N_{\text {Paris, cycles }}^{\dagger}\end{array}$ \\
\hline 30 & $\begin{array}{l}208 \\
218\end{array}$ & 213 & $\begin{array}{l}326 \\
323\end{array}$ & 324 & $7.3 \mathrm{E}-12$ & 213 \\
\hline 480 & $\begin{array}{l}162 \\
169 \\
130\end{array}$ & 154 & $\begin{array}{l}323 \\
339 \\
332\end{array}$ & 331 & $9.0 \mathrm{E}-12$ & 172 \\
\hline 1800 & $\begin{array}{l}96 \\
85 \\
93\end{array}$ & 91 & $\begin{array}{l}346 \\
346 \\
352\end{array}$ & 348 & $1.18 \mathrm{E}-11$ & 132 \\
\hline
\end{tabular}

\footnotetext{
${ }^{*} C_{\text {Paris }}$ values are calculated with the Paris' law, Eq. [1], such that the lifetime corresponds to the average experimental lifetime, using the actual stress levels and assuming $m=5$.

'Lifetimes are calculated using a maximum stress level of $324 \mathrm{MPa}$.

${ }^{\ddagger} C_{\text {Paris }}$ values give $d a / d N$ in $\mathrm{m} /$ cycle, when $\Delta K$ is expressed in $\mathrm{MPa} \sqrt{\mathrm{m}}$.
} 
(tensile) stress $\left(\sigma_{\max }\right)$ has dropped by 10 pct relative to its maximum value.

The TMF lifetime results for different holding times show a clear reduction in lifetime, at prolonged holding times (Table II). Relative to the lifetime at 30 seconds holding (i.e., 213 cycles), the lifetimes for the $480 \mathrm{sec}$ onds and 1800 seconds holding times show a reduction of 28 pct and $57 \mathrm{pct}$, respectively. As reported in our previous work, ${ }^{[7]}$ for a holding time of 480 seconds, a reduction in lifetime of the same order was found for the smooth specimens (i.e., 35 pct reduction in $N_{10}$ ).

The effect of holding time can also be evaluated in relation to the developed stress levels during the progress of the TMF experiment. In Figure 4, a typical development of the minimum, mean, and maximum stress is shown as a function of elapsed TMF cycles for the holding times tested. The development of stress levels can be divided into three distinct regions. ${ }^{[3]}$

The first region is characterized by increases in minimum and maximum stress level for subsequent TMF cycles. In the second region, the maximum stress level remains more or less stable. Finally, in the third region, a drop in stress level is observed. For the total constraint tests applied here, the drop in maximum tensile stress is induced by a decrease in specimen stiffness, associated with the opening of a macroscopic crack. Therefore, the drop in stress level can be used to detect a macroscopic crack and can be applied as a criterion to define TMF lifetime. In Reference 3, the number of cycles at a 25 pct drop in stress level (i.e., $N_{25}$ ), is suggested as the TMF lifetime. However, in our previous research, ${ }^{[7]}$ it was found that a $10 \mathrm{pct}$ drop in stress is a more consistent criterion (i.e., $N_{10}$ ), leading to less scatter. In Section III-B, the underlying reasons for using $N_{10}$ as the lifetime criterion are discussed in more detail. For the TMF lifetime results presented in Table II, the $N_{10}$ lifetime criterion was adopted.

TMF testing under total constraint is equivalent to cyclically inducing a fixed amount of mechanical strain.

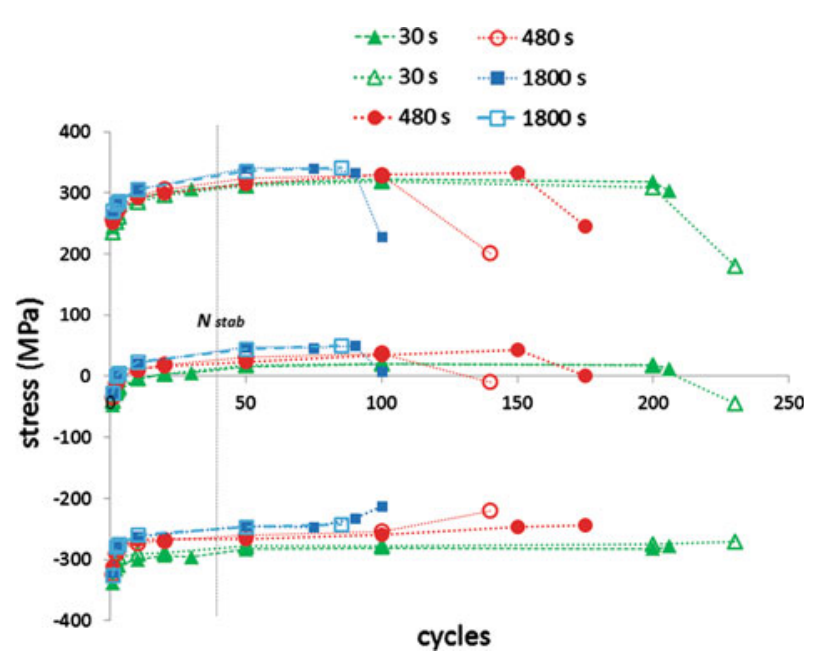

Fig. 4-Maximum, mean and minimum stresses as a function of TMF cycles with holding times of $30 \mathrm{~s}, 480 \mathrm{~s}$, and $1800 \mathrm{~s}$.
This amount is equal (and opposite in sign) to the value of the thermal strain, which was 0.6 pct for the TMF tests under consideration, corresponding to the temperature range of $323 \mathrm{~K}$ to $693 \mathrm{~K}\left(50{ }^{\circ} \mathrm{C}\right.$ to $\left.420{ }^{\circ} \mathrm{C}\right)$.

Therefore, during the entire duration of the TMF tests, the CGI material is exposed to strain changes of 0.6 pct in the tensile direction during cooling and the compressive direction during heating. The resulting stress levels largely depend on the initial stress levels from which individual strain excursions start. Therefore, the development of tensile and compressive stresses during a TMF test, under conditions of total constraint, are mutually dependent.

As can be seen in Figure 4, for all holding times, the mean stress level shifts towards a tensile value during the progress of the TMF test. This is typical for the out-ofphase nature of the TMF loading condition under total constraint. One reason for the shift is that the material exhibits a lower yield strength in the compressive region (at high temperature) compared to the value in the tensile region (at low temperature). In addition, the compressive stress may decrease during the holding time at high temperatures because of stress relaxation. As a consequence, the strain cycle associated with cooling starts at a relatively low compressive stress and will, thus, produce a relatively high tensile stress. Moreover, the subsequent heating cycle starts from this relatively high tensile stress, resulting in a relatively low compressive stress. This process is repeated until the ratio of tensile and compressive stresses settles to a certain stable value.

The stress-mechanical strain hysteresis can also give useful information about the TMF behavior. The mechanical strains calculated as a function of stress for one of the specimens $\left(N_{10}=96, c f\right.$. Table II) with a 1800 seconds holding time are shown in Figure 5. The black circle indicates the parts of the TMF cycles where the compressive stress relaxes. It can also be observed that the lower the compressive stress, the higher the tensile stress in the next cycle, confirming the

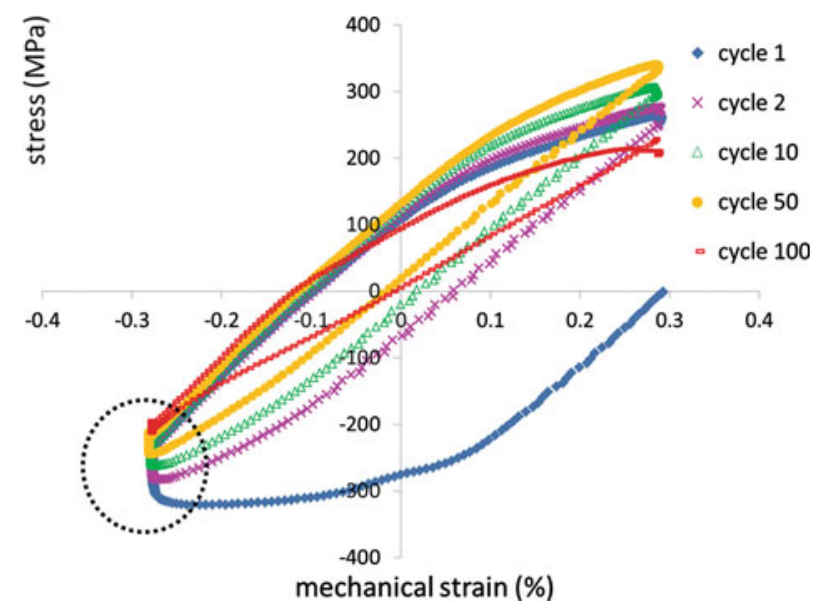

Fig. 5- Stress-mechanical strain hysteresis loops for a specimen with $1800 \mathrm{~s}$ holding time $\left(N_{10}=96\right.$, $c f$. Table II), revealing the development of the maximum tensile stress with increasing cycles due to stress relaxation. 


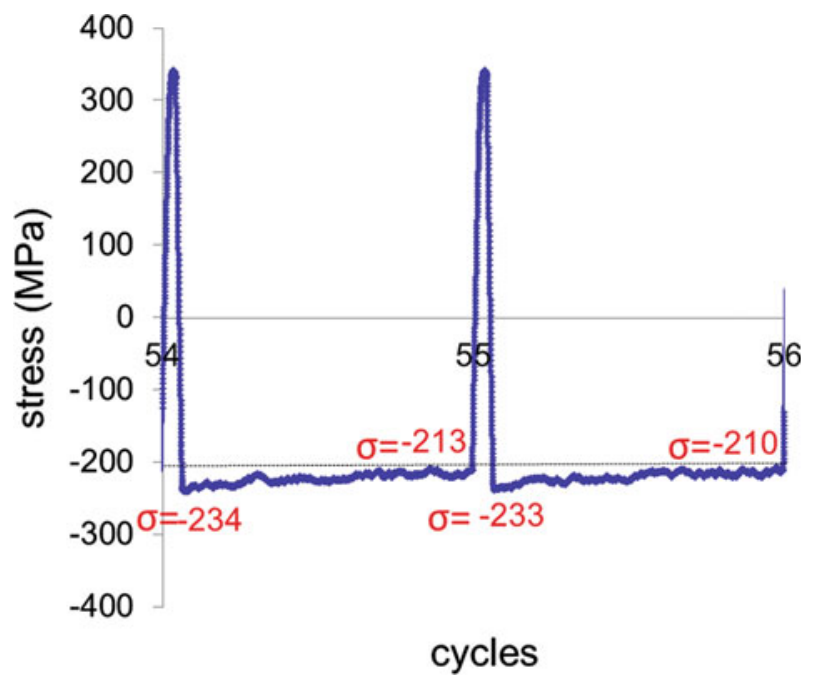

Fig. 6- Stress as a function of time for two cycles (55 and 56) of specimen with $1800 \mathrm{~s}$ holding time $\left(N_{10}=96\right)$.

interdependency of tensile and compressive stress levels, as described before.

With progressing TMF cycles, the amount of stress relaxation at $693 \mathrm{~K}\left(420{ }^{\circ} \mathrm{C}\right)$ gradually decreases and the shape of the hysteresis loop becomes narrower, indicating a reduction of cyclic plasticity.

In Figure 6, the stress is plotted as a function of time for two cycles (55 and 56) for the specimen discussed above (Figure 5). The stress relaxation at $693 \mathrm{~K}$ $\left(420{ }^{\circ} \mathrm{C}\right)$ for these two cycles is approximately $22 \mathrm{MPa}$. On the other hand, the increase of $\sigma_{\max }$ by changing the holding time from 30 seconds to $1800 \mathrm{sec}-$ onds is approximately $24 \mathrm{MPa}$ ( $c f$. Table II). Therefore, it can be inferred that the higher stress relaxation occurring during 1800 seconds holding time is responsible for the increase of $\sigma_{\max }$.

The evolution of the amount of stress relaxation during the holding time under compression with the number of TMF cycles is plotted for all three holding times in Figure 7. This stress relaxation is calculated as the stress change from the moment the temperature has stabilized at $693 \mathrm{~K}\left(420{ }^{\circ} \mathrm{C}\right)$ (after 10 seconds exposure) until the last moment of exposure to $693 \mathrm{~K}\left(420^{\circ} \mathrm{C}\right)$. As can be seen, the stress relaxation for the 480 seconds and 1800 seconds holding times show a similar trend, starting at a high level of about $50 \mathrm{MPa}$ and reducing to a level of about $22 \mathrm{MPa}$ after 50 cycles, and then remaining at that level. The stress relaxation for the specimen with 30 seconds holding time has a much lower value of about $10 \mathrm{MPa}$ for the entire duration of the TMF test. Relaxation of stresses is thought to be related to viscous phenomena and recovery processes. ${ }^{[3]}$ This is investigated by EBSD techniques and will be discussed in Section III-D.

In Figure 5, the decrease in cyclic plastic strain can already be observed, but in Figure 8 , the reduction of cyclic plasticity is presented more clearly. The calculated plastic strain range $v s$ the number of elapsed cycles is plotted for all three holding times. The plastic strain range is calculated by subtracting the elastic strain range

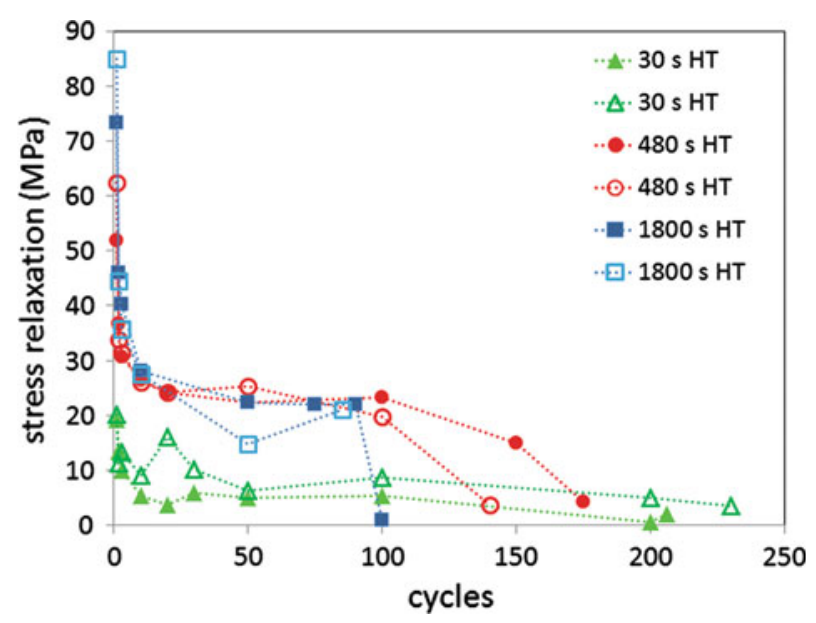

Fig. 7-Stress relaxation vs number of cycles, compared for three specimens with $30 \mathrm{~s}, 480 \mathrm{~s}$, and $1800 \mathrm{~s}$ holding time.

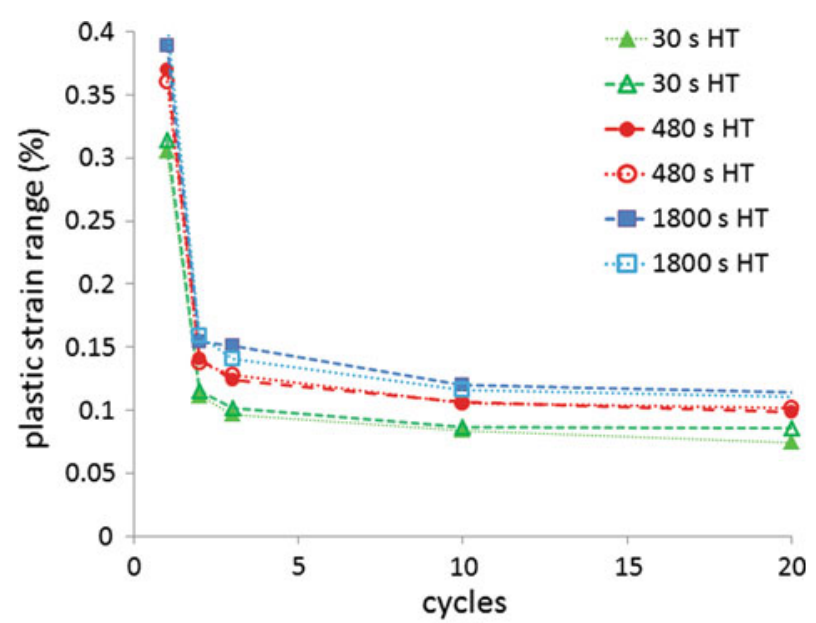

(a)

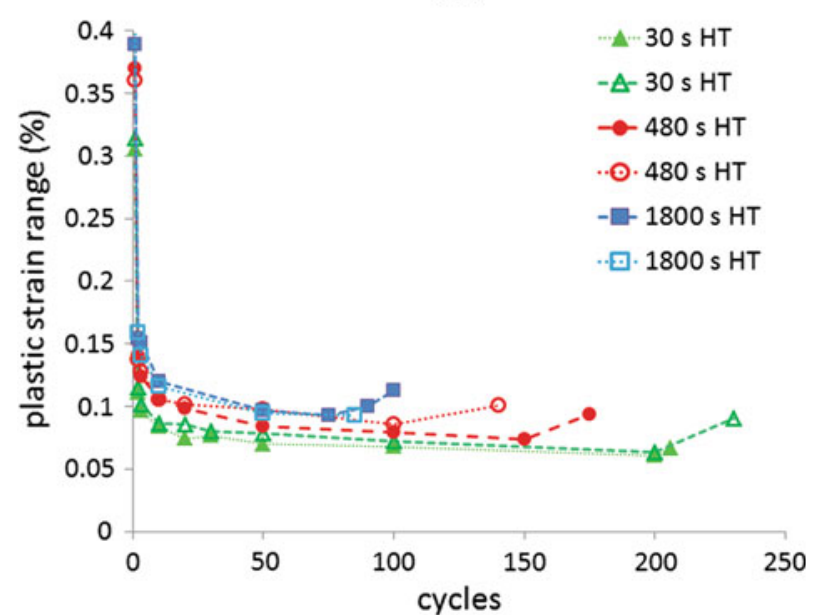

(b)

Fig. 8-Plastic strain range vs number of cycles, compared for three specimens with $30 \mathrm{~s}, 480 \mathrm{~s}$, and $1800 \mathrm{~s}$ holding time: (a) first 20 cycles and $(b)$ complete lifetime. 
from the mechanical strain range. The maximum and minimum elastic strains needed to calculate the elastic strain range are calculated as the maximum and minimum stresses divided by the Young's moduli at the minimum and maximum temperature, respectively.

All holding times show a similar trend of a rapidly decreasing plastic strain range in the first few cycles, continuing to decrease at a somewhat slower pace in the first tens of cycles, saturating at a nearly constant value from 50 cycles onwards, and increasing somewhat at the end of the test. The reduction in cyclic plasticity is in accordance with an increase in yield strength found at increased numbers of cycles. This increase in strength indicates the occurrence of cyclic strain hardening. It should be noted that at the start of the test, the total constraint condition was applied at the minimum temperature, and consequently, the first TMF cycle produces a large compressive plasticity in the CGI. In the 2 nd cycle (the first complete cycle), the plastic strain range $\Delta \varepsilon_{\mathrm{p}}$ is already significantly lower.

The levels of cyclic plastic strain differ for the different holding times, with the highest cyclic plasticity for the longest holding time. It seems likely that a high cyclic plasticity contributes to the shorter lifetime at prolonged holding times.

\section{B. The Relation Between Extensometer Position and Load Drop Behavior}

It was found that the load drop related to the development of a macroscopic crack is not always consistent. Sometimes, a considerable degree of load drop occurred before final fracture, while in some other cases, sudden fracture took place without any load drop. It should be mentioned that the (final) main crack is typically asymmetrical ( $c f$. Figure 9) and initiates randomly relative to the position of the extensometer. Therefore, the extensometer could be positioned at the crack mouth location or opposite to it. To analyze this matter, we marked the extensometer position on the tested specimens. From this, we observed a relation between the aforementioned load drop behavior and the position where the main fatigue crack developed relative to the extensometer. Typically, when the crack mouth of the final crack was on the same side as the extensometer, a substantial load drop occurred before failure, and the final crack lengths were relatively large.

The effect of the extensometer position can be related to the asymmetry of the dominant fatigue crack, which introduces a bending component in the specimen. If this crack develops at the extensometer position, the displacement experienced by the extensometer during tensile loading is relatively large, due to opening of the crack. In this case, the control system applies only a relatively low tensile load on the specimen to maintain the total constraint condition at low temperature. Since the crack is now loaded to a lesser extent, it can grow to a larger size before it becomes critical and leads to failure. More cycles are needed for failure to occur, during which the maximum tensile load will drop substantially as a result of the decreasing specimen stiffness. Conversely, when the dominant crack develops diametrically
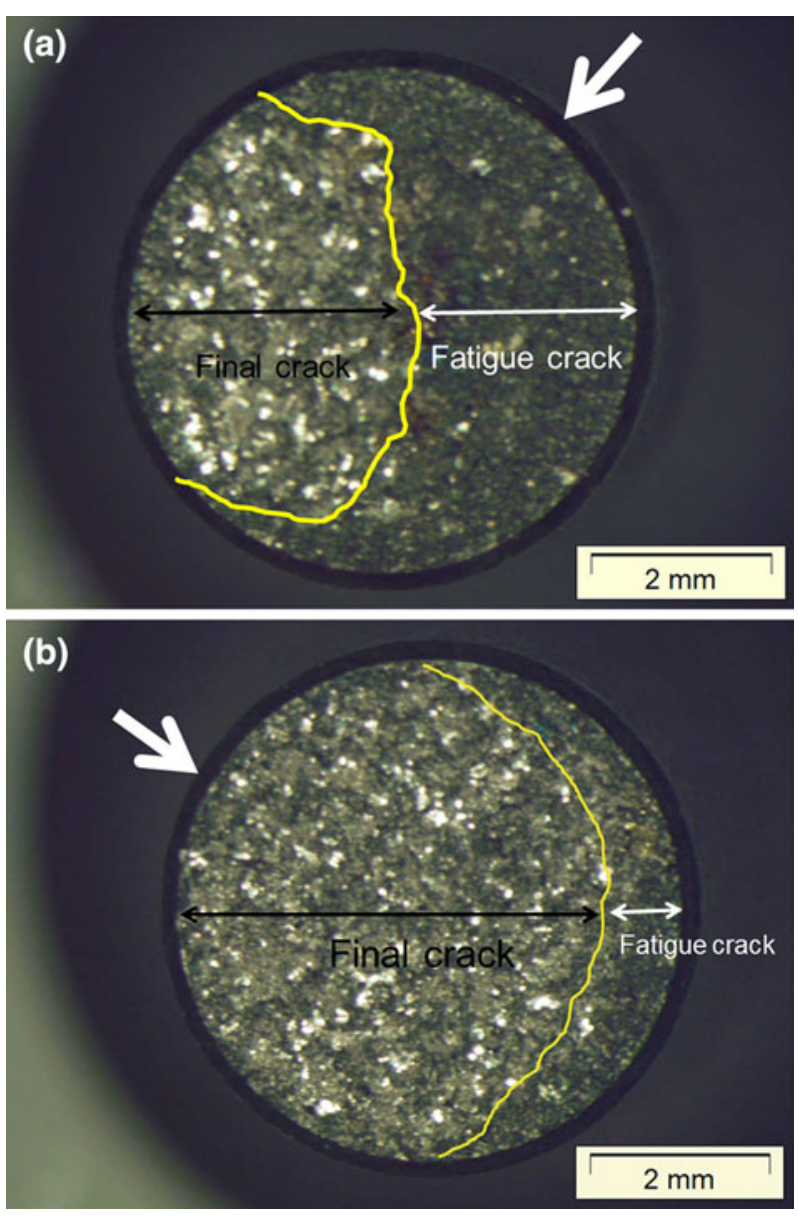

Fig. 9- Holding time $1800 \mathrm{~s}$ : (a) $N_{10}=96$, with the extensometer at the crack mouth and $(b) N_{10}=85$, the extensometer is at the opposite side of the crack.

opposed to the extensometer, an opposite observation can be made. The extensometer now experiences relatively low displacements, and correspondingly high external tensile loads are required to maintain the total constraint condition. Failure will occur at a shorter length of the dominant crack, involving only a small load drop.

In order to reduce the influence of the extensometer position on TMF lifetime, the failure criterion for TMF lifetime is defined as the number of cycles at a $10 \mathrm{pct}$ load drop. At such a small load drop, the crack is still relatively short and the bending effect will be less pronounced; consequently, the effect of the extensometer position will be effectively reduced.

\section{Theoretical Approach: Lifetime Prediction Using The Paris Crack Growth Law}

In our previous work, ${ }^{[7]}$ the failure times were calculated successfully by applying the Paris' fatigue crack growth law

$$
\frac{d a}{d N}=C\left(\Delta K_{\mathrm{I}}\right)^{m}
$$

where $a$ is the crack size (m), $N$ is the number of cycles, $\Delta K_{\mathrm{I}}$ is the stress intensity range $(\mathrm{MPa} \sqrt{\mathrm{m}})$, and $C$ and $m$ 
are material-dependent parameters. The stress intensity range is corrected for crack closure at compressive loads by simply assuming $\Delta K=K_{\max }$. In the calculation, it is assumed that a crack initiates immediately from the notch, i.e., the depth of the circumferential notch is taken as the initial crack length. Assuming specific values for $C$ and $m$, the number of cycles is calculated for a first crack extension of $0.01 \mathrm{~mm}$ around the entire circumference of the specimen. This process is repeated for subsequent steps of $0.01 \mathrm{~mm}$, adjusting $\Delta K$ in each step in accordance with the increased crack length. By applying this numerical procedure, the number of cycles $N$ is calculated for reaching $1.5 \mathrm{~mm}$ of crack extension, which corresponds to 50 pct of the sample diameter. This limit is considered here as the critical crack length for sample failure. Thus, lifetime is calculated on the basis of crack growth kinetics, i.e., the Paris's law, rather than by the crack-initiation rate. In the case of a notched sample in CGI, this condition is likely to be fulfilled. The values for $\Delta \mathrm{K}$ ranged from $10 \mathrm{MPa} \sqrt{\mathrm{m}}$ to $40 \mathrm{MPa} \sqrt{\mathrm{m}}$, representing the levels of $\Delta \mathrm{K}$ for the initial crack length $(0.2 \mathrm{~mm})$ and final crack length $(1.5 \mathrm{~mm})$, respectively.

The model accounts for the maximum stress level developed, so the theoretical effect of different maximum stress levels found at different holding times can be evaluated. In Table II, the calculated values for the parameter $C$ are shown for which the calculated and measured lifetimes are the same at each holding time. The $m$ parameter value is assumed to be 5 , as used in our previous work. ${ }^{[7]}$ It must be noted that the $C$ value for the 30 seconds holding time $7.3 \times 10^{-12}$ is not the same as found earlier, i.e., $9.5 \times 10^{-12}{ }^{[7]}$ The difference is probably related to the fact that the tested specimens were sampled from different cylinder heads with different batch properties.

As can be seen in Table II and in Figure 4, increasing the holding time leads to higher maximum stress levels and shorter lifetimes. In order to see the isolated effect of holding time without the influence of increasing stress level, a corrected lifetime is calculated using the same maximum stress level for all holding times, while using the $C$ values mentioned in Table II. This stress level was chosen to be the value that occurred for the shortest holding time, i.e., $324 \mathrm{MPa}$. The corrected calculated lifetimes $\left(N_{\text {Paris }}\right)$ are shown in the last column of Table II.

In Figure 10, the experimental $N_{10}$ values and the calculated $N_{\text {Paris }}$ values are plotted for the three holding times under consideration. As can be seen, the reduction in lifetime is less pronounced for the calculated results. Therefore, according to the calculations of the corrected lifetimes, the higher tensile stress levels that developed during the 1800 seconds holding time tests do not completely account for the measured reduction in lifetime. This might point to an additional effect related to stress relaxation during holding at high temperature.

\section{EBSD Results}

The evolution of the crystal misorientation angle in the range between $0 \mathrm{deg}$ and $10 \mathrm{deg}$ is an indication of local strains induced in the microstructure by the compressive stresses involved in these thermomechanical treatments. Such stresses produce plastic deformation, involving dislocation glide in the metal matrix. The dislocations remaining in the microstructure configure themselves in cells or subgrains, which will give rise to small orientation gradients that can be measured accurately by orientation contrast microscopy (EBSD with angular resolution of the order of less than $1 \mathrm{deg}$ ).

Table III contains the area fraction (pct) of low-angle grain boundaries (LAGB) measured with EBSD at a specific location of the parallelepipoid-shaped CGI specimen in three conditions. As can be seen Table III, the as-cast condition gives 64 pct of LAGB area fraction, whereas after heating to $693 \mathrm{~K}\left(420^{\circ} \mathrm{C}\right)$ in total constraint (1st step), this has increased to 73 pct, clearly showing the effect of plasticity to which the sample was subjected. However, after a holding time of 1800 seconds (2nd step), the LAGB area fraction has regressed to the initial value. Alternatively, this trend can also be observed in Figure 11, exhibiting the image quality maps of the three conditions under consideration (the image quality factor represents a quantitative

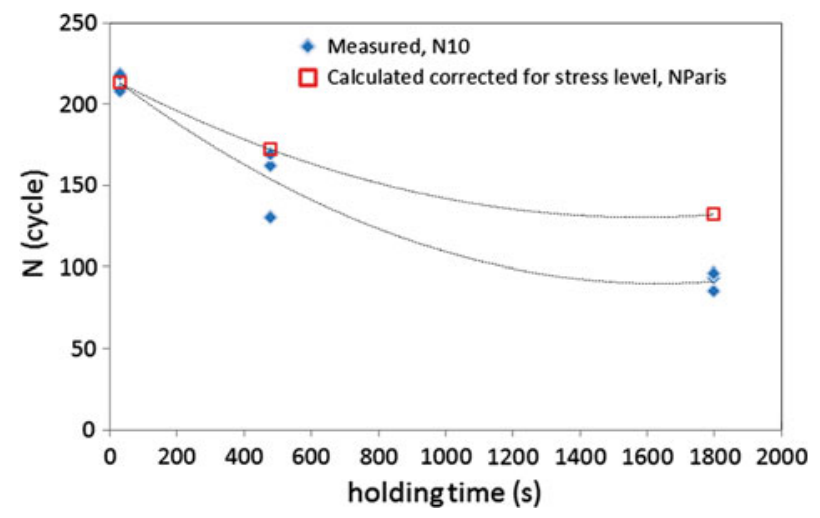

Fig. 10-Measured lifetimes and lifetimes calculated while correcting for stress level, both as a function of holding time.

Table III. Quantitative Data Obtained from EBSD Scans: Volume Fraction of LAGBs (0 to $10 \mathrm{deg}$ ) and Kernel Average Misorientation

\begin{tabular}{|c|c|c|}
\hline Specimen Condition & $\begin{array}{l}\text { Misorientation } \\
\text { Angle } \\
0 \text { to } 10 \mathrm{deg} \\
\text { (pct) }\end{array}$ & $\begin{array}{c}\text { Kernel } \\
\text { Average } \\
\text { Misorientation } \\
\text { (Standard } \\
\text { Deviation) }\end{array}$ \\
\hline $\begin{array}{l}\text { As-cast condition } \\
\text { (point A in Fig. 3) }\end{array}$ & 64 & $0.62(2.44 \mathrm{pct})$ \\
\hline $\begin{array}{l}\text { 1st step: Heating } \\
\text { to } 693 \mathrm{~K}\left(420{ }^{\circ} \mathrm{C}\right) \\
\text { under total } \\
\text { constraint } \\
\text { (point B in Fig. 3) }\end{array}$ & 73 & $0.73(2.21 \mathrm{pct})$ \\
\hline $\begin{array}{l}\text { 2nd step: After } \\
1800 \mathrm{~s} \\
\text { holding time } \\
\text { at } 693 \mathrm{~K}\left(420{ }^{\circ} \mathrm{C}\right) \\
\text { (point } \mathrm{C} \text { in Fig. } 3 \text { ) }\end{array}$ & 65 & $0.68(2.15 \mathrm{pct})$ \\
\hline
\end{tabular}



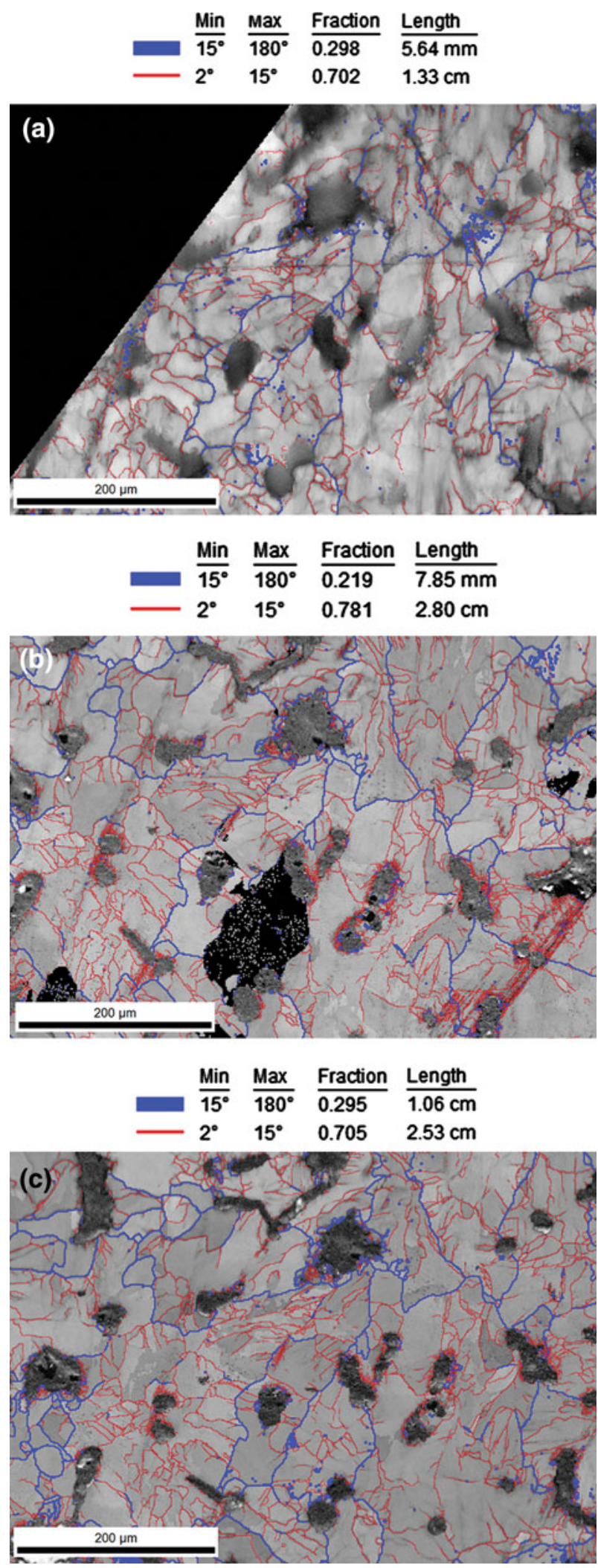

Fig. 11-Image quality maps of three conditions under consideration: (a) as-cast condition, (b) 1st step: heating to $693 \mathrm{~K}\left(420{ }^{\circ} \mathrm{C}\right)$ in total constraint, and $(c)$ 2nd step: after $1800 \mathrm{~s}$ holding time at $693 \mathrm{~K}$ $\left(420{ }^{\circ} \mathrm{C}\right)$. measure of the band contrast in the EBSD pattern, and therefore, it is indicative of the local density of crystal defects). In these maps, LAGBs (2 to15 deg) together with high-angle grain boundaries, 15 to $180 \mathrm{deg}$ ) are indicated by red (thin) and blue (thick) lines, respectively.

Local misorientation can also be characterized using a misorientation kernel approach, which quantifies the average misorientation of a data pixel in the EBSD scan with regard to its 1 st, 2 nd, or $n$th nearest neighbors. The resulting parameter of this analysis is the so-called kernel average misorientation (KAM) value associated with each individual data point.

Table III lists the average KAM values for 1st nearest neighbors for the entire scan (excluding the graphite phase) observed in the three conditions considered. It should be noted that the average KAM value is sensitive to the plastic strain occurring after heating the sample from $323 \mathrm{~K}$ to $693 \mathrm{~K}\left(50{ }^{\circ} \mathrm{C}\right.$ to $\left.420{ }^{\circ} \mathrm{C}\right)$, as its value increases from $0.62 \mathrm{deg}$ to $0.73 \mathrm{deg}$. After a holding time of 1800 seconds at this temperature, the average KAM value drops to $0.68 \mathrm{deg}$, which is precisely half way the value of the 1st step and the as-cast condition, cf. Table III.

Figure 12 also displays the KAM distributions between 0 and $5 \mathrm{deg}$ for the three conditions under consideration. It can be observed that there is a slight difference in the tail end of the distribution, in the range of 1 to $3 \mathrm{deg}$, between the samples that were subjected to a plastic strain of 0.4 pct (imposed by the mechanical constraint) and the initial sample in as-cast condition. After holding for 1800 seconds at high temperature, the

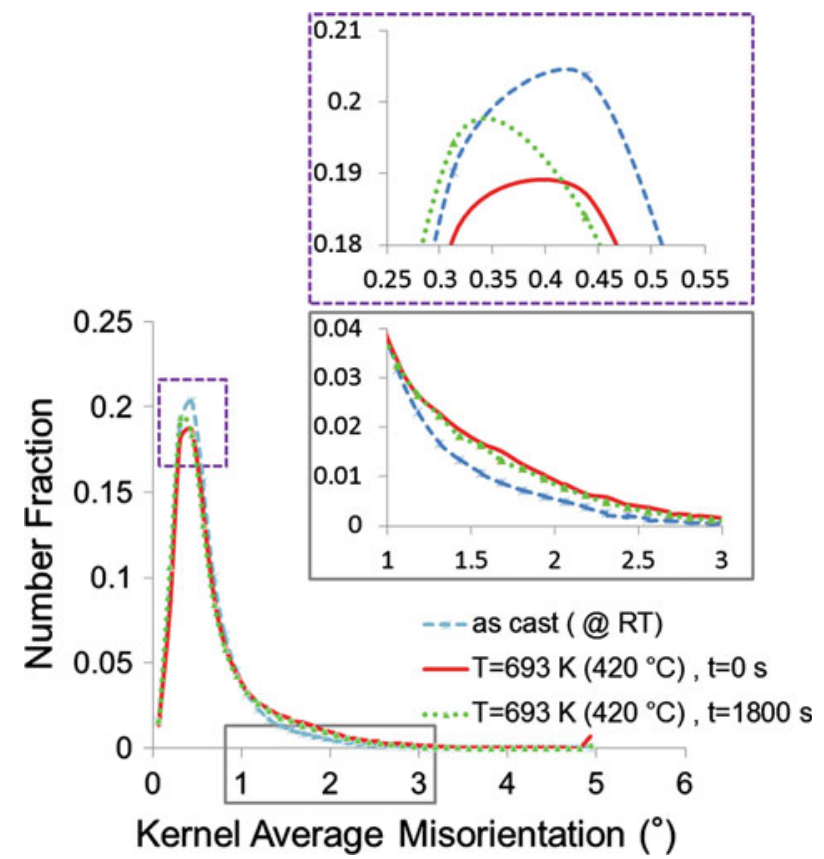

Fig. 12-KAM distribution for the three conditions under consideration: as-cast, heating to $693 \mathrm{~K}\left(420^{\circ} \mathrm{C}\right)$ in total constraint, and after $1800 \mathrm{~s}$ holding time at $693 \mathrm{~K}\left(420^{\circ} \mathrm{C}\right)$. 
peak position or the distribution average is affected by the stress relaxation during isothermal holding time; i.e., one may readily assume that the sample was subjected to stress relieve recovery. By close inspection of the KAM distribution profiles, it can be observed that this gave rise to a slight shift of the distribution peak from 0.44 deg at the start to $0.31 \mathrm{deg}$ at the end of the holding. This is also reflected in a drop of the average KAM value from $0.73 \mathrm{deg}$ to $0.68 \mathrm{deg}$. This may be associated with the fact that the deformation substructure, established by plastic deformation, is predominantly reflected in the high tail of end the distribution, whereas statistical scatter of short-range orientation gradients more affects the bulk of the distribution. In this sense, one may draw the conclusion that the relaxation processes have left the plastic deformation structure unchanged but have reduced to some extent the local orientation scatter, corresponding to the well-known recovery of statistically stored dislocations in the metal matrix. ${ }^{[12]}$ Whether these minute changes are truly representative for the underlying microstructural changes needs to be confirmed in further study.

\section{CONCLUSIONS}

With respect to the TMF tests under total constraint between $323 \mathrm{~K}$ and $693 \mathrm{~K}\left(50{ }^{\circ} \mathrm{C}\right.$ and $\left.420^{\circ} \mathrm{C}\right)$ performed on pearlitic CGI samples, the following is concluded:

- TMF lifetime was found to decrease by approximately 60 pct, when holding times at $693 \mathrm{~K}\left(420^{\circ} \mathrm{C}\right)$ were increased from 30 seconds to 1800 seconds.

- The maximum stress level (tension) that develops during tests was found to be higher at prolonged holding times. This is shown to be caused by the pronounced stress relaxation in compression at longer holding times.

- The Paris fatigue crack growth model is used to calculate lifetimes, compensated for different stress levels that developed at prolonged holding times. It was found that after correcting for the differences in maximum stress level, an increase in holding time from 30 seconds to 1800 seconds can account for a 38 pct reduction in lifetime, indicating some timedependent failure mechanism(s) during TMF.

- EBSD results reveal the evolution of the microstructure of CGI in relation with the thermomechanical treatment. Quantitative data obtained from EBSD scans confirmed that after heating to $693 \mathrm{~K}\left(420^{\circ} \mathrm{C}\right)$ under total constraint, the induced strain gives rise to higher LAGB area fraction, while after $1800 \mathrm{sec}-$ onds holding time, this fraction has regressed to the initial value. This may be indicative of the recovery process during holding. The recovered state is different from the initial state, however, as the high end tail of the KAM distribution function does not revert to the initial as-cast condition. Therefore, it can be concluded that recovery modifies the plastically strained condition but does not bring it back to the undeformed state.

\section{ACKNOWLEDGMENTS}

This research was carried out under project number MC2.06270 in the framework of the Research Program of the Materials innovation institute, M2i (www.m2i.nl). The authors would like to thank DAF TRUCKS N.V. Central Laboratories for their contributions and provision of material for this research.

\section{OPEN ACCESS}

This article is distributed under the terms of the Creative Commons Attribution License which permits any use, distribution, and reproduction in any medium, provided the original author(s) and the source are credited.

\section{REFERENCES}

1. S. Trampert, T. Gocmez, and S. Pischinger: J. Eng. Gas Turbines Power, 2008, vol. 130, pp. 012806-1.

2. D. Löhe, T. Beck, and K. Lang: Fifth Int. Conf. on Low Cycle Fatigue, P.D. Portella, H. Sehitoglu, and K. Hatanaka, eds., LCF5, DVM, Berlin, Germany, 2004, pp. 161-175.

3. E. Charkaluk and L Remy: Fatigue of Materials and Structures, Application to Design and Damage, C. Bathias and A. Pineau, eds., Wiley, New York, NY, 2011, pp. 271-338.

4. T. Gocmez, A. Awarke, and S. Pischinger: Int. J. Fatigue, 2010, vol. 32, pp. 769-79.

5. T. Seifert and H. Riedel: Int. J. Fatigue, 2010, vol. 32, pp. 13581367.

6. T. Seifert, G. Maier, A. Uihlein, K. Lang, and H. Riedel: Int. J. Fatigue, 2010, vol. 32, pp. 1368-77.

7. S. Ghodrat, A. Riemslag, and M. Janssen: Delft University of Technology, Delft, the Netherlands, unpublished research, 2012.

8. R. Gundlach: AFS Trans., 1979, vol. 61, pp. 551-60.

9. F. Zieher and F. Langmayr: "Engine Simulation in View of Reduced Development Time." Technical, Paper Code: F02V081, AVL List GmbH, Austria, 2002.

10. J. Zuidema, L. Wijnmaalen, and C. van Eldijk: Fatigue, 1999, vol. 3, pp. 2071-76.

11. P. Hähner, C. Rinaldi, V. Bicego, and E. Affeldt: Int. J. Fatigue, 2008, vol. 30, pp. 372-81

12. F.J. Humphreys and M. Hatherly: Recrystallization and Related Annealing Phenomena, Recovery after Deformation, Elsevier Ltd., Atlanta, GA, 2004, pp. 169-213. 